\title{
A system of vectors for Bacillus subtilis spore surface display
}

\author{
Adam Iwanicki ${ }^{* \dagger}$, Iwona Piątek ${ }^{\dagger}$, Małgorzata Stasiłojć, Anna Grela, Tomasz Łęga, Michał Obuchowski \\ and Krzysztof Hinc
}

\begin{abstract}
Background: Bacterial spores have been utilized as platforms for protein display. The best studied display systems are based on Bacillus subtilis spores in which several coat proteins have successfully been used as anchors for heterologous protein. Increasing knowledge about spore coat structure enables selection of new anchor proteins such as CotZ and CgeA. Here we describe a system of vectors for display of proteins on the surface of B. subtilis spores.
\end{abstract}

Results: We have designed and constructed a set of 16 vectors for ectopic integration which can be used for spore surface display of heterologous proteins. There is a selection of five coat proteins: CotB, CotC, CotG, CotZ and CgeA which can be used for construction of fusions. Three of these (CotB, CotC and $\operatorname{Cot} G$ ) enable obtaining N-terminal and C-terminal fusions and other two (CotZ and CgeA) are designed to produce C-terminal fusions only. All the vectors enable introduction of an additional peptide linker between anchor and displayed protein to enhance surface display. As a selection marker trophic genes are used. Additionally we describe an example application of presented vector system to display CagA protein of Helicobacter pylori in fusion with CgeA spore coat protein.

Conclusions: Described system of vectors is a versatile tool for display of heterologous proteins on the surface of B. subtilis spores. Such recombinant spores can be further used as for example biocatalysts or antigen-carriers in vaccine formulations. The lack of antibiotic resistance genes in the system makes such spores an interesting option for applications in which a possible release to the environment can occur.

Keywords: Bacillus subtilis, Spore display, Ectopic integration vectors

\section{Background}

The targeting and anchoring of heterologous proteins and peptides to the outer surface of bacteriophages and cells is becoming a tool for research in the fields of microbiology, molecular biology or vaccinology, as well as is utilized in the biotechnological industry. This approach is based on the idea of using naturally occurring surface proteins as an anchor for targeting proteins of interest, also called passenger proteins. Such recombinant phages or cells can be used in many applications, to mention only a few examples, such as vaccine vehicles, carriers of active enzymes and antibodies, biosensors (for review see $[1,2-4])$. The main problem concerning

\footnotetext{
*Correspondence: aiwanicki@gumed.edu.pl; krzysztof.hinc@biotech.ug.edu.pl ${ }^{\dagger}$ Equal contributors

Department of Medical Biotechnology, Intercollegiate Faculty of Biotechnology UG-MUG, Medical University of Gdańsk, Dębinki 1, Gdańsk
} 80-211, Poland

\section{Biomed Central}

usage of these systems is connected with the need of the chimeric protein to cross the cytoplasmic membrane. Not every chimera is able cross this barrier resulting in failure of surface display. Most of these limitations can be overcome by using bacterial endospores. Classic examples of spore forming microorganisms are bacteria from genus Bacillus. Formation of endospores is a strategy used by these bacteria to survive unfavorable and growth-restricting conditions. Bacillus is well known aerobic bacterium widely used for production of industrial proteins. It is classified as a GRAS organism (generally recognized as safe), possesses low trophic requirements and serves as a model Gram-positive microorganism. One of the main advantages of Bacillus spores as vehicles for surface display of proteins is that these structures are formed inside of mother cell in natural process of 
sporulation. Additionally, a set of molecular chaperones active in the cytoplasm of bacteria can facilitate proper folding of the heterologous protein.

The process of sporulation is controlled by a multistep developmental program starting with formation of polar septum. Upon formation of asymmetric compartments the mother cell initiates the engulfment of the forespore, which upon completion of this process becomes doublemembrane bound structure. As the engulfment proceeds two external protective layers are built: the cortex, composed of peptidoglycan [5], assembled between the inner and outer forespore membranes, and the proteinaceous coat, the outermost spore layer [6,7]. The central part of the spore is the core, containing partially dehydrated cytoplasm.

The spore coat is composed of at least 70 individual proteins, which are produced in the mother cell [8] and consists of three distinct layers: a lamellar inner coat, a more coarsely layered outer coat and the crust $[9,10]$. While five proteins are crucial for proper spore coat formation (SpoIVA, SpoVM, SpoVID, SafA and CotE) and therefore they are called morphogenetic proteins [11], another three proteins, $\operatorname{Cot} \mathrm{X}, \operatorname{Cot} \mathrm{Y}$ and $\operatorname{CotZ}$, have been shown to be morphogenes of the crust [11,12].

So far four spore coat proteins have been used for display of enzymes or antigens in spore based vaccines. These are CotB, CotC, CotG and CotX. All of them are located in the outermost layer of the coat. CotB protein has been used for display of C-terminal part of Clostridium tetani toxin [13], 1b-3 and 4 domains of the Protective Antigen of Bacillus anthracis [14] and subunit A of Helicobacter acinonychis urease [15]. This last one has also been displayed using $\operatorname{Cot} C$ and $\operatorname{Cot} G$ proteins. CotC served as an anchor for such proteins as teugmental protein of Clonorchis sinensis [14] or human serum albumin [16]. CotG protein has been used for display of GFP [17] or heterologous enzymes [18,19]. Recently, a crust protein CotZ has been shown to be a good candidate as a new anchor protein useful in spore surface display [20].

Here we present a system of 16 integration vectors which can be used for display of heterologous proteins on the spore surface utilizing $\operatorname{Cot} B, \operatorname{Cot} C, \operatorname{Cot} G, \operatorname{Cot} Z$ or CgeA spore coat proteins. Vectors are prepared in the way enabling for cloning a gene of interest to at the $\mathrm{N}$ or C-terminus of a gene coding for spore coat protein with an optional peptide linker. Each vector harbors proper trophic gene, which ensures genetic stability and selection for appropriate recombinant strains. Lack of antibiotic resistance genes makes the use of such vector system safe in case of applications in which prepared recombinant spores could enter the environment. Such system could be easily used for preparation of sporebased vaccines or as biocatalysts.

\section{Results and discussion}

\section{The design of pCot vectors}

The prototype vector of the pCot set has the following properties. (i) It cannot replicate in B. subtilis but carries ColE1 replication sequences and a $\beta$-lactamase gene for amplification in E. coli. (ii) The cot/cgeA gene is cloned along with its original promoter to ensure proper expression of obtained fusion protein. Depending on the designation of the vector a cloning site is introduced either at the N- or C-terminus of the cot gene. (iii) Genetic stability and selection of recombinant strains is possible due to presence of selection marker - a trophic gene cassette enabling for complementation in recipient auxotrophic strain. It is worth stressing out that no antibiotic resistance gene selectable in B. subtilis is introduced into the vectors. Such design of the system is especially important for applications in which recombinant spores can be released to the environment. In that case it prevents from shedding the antibiotic resistant bacteria. A trophic gene cassette is cloned downstream of the $\cot$ gene to prevent transcription interference. (iv) The cot/cgeA gene along with trophic gene cassette is flanked by fragments of non-essential gene to enable ectopic integration into the chromosome of recipient strain.

Five spore coat proteins have been selected as carriers of heterologous proteins. The usefulness of four proteins $\operatorname{Cot} B, \operatorname{Cot} C, \operatorname{Cot} G$ and $\operatorname{Cot} Z$ for such application has already been shown. Additionally a crust protein CgeA has also been selected.

In case of well described CotBCG proteins we decided to prepare four variants of the vectors. Two enable producing recombinant protein fused to C-terminus of Cot protein while the other two are designed for $\mathrm{N}$-terminal fusions. Each pair consists of one version of vector in which recombinant protein is linked directly to Cot protein and the other with short peptide linker (-GGGGS-). The vectors with $\cot Z$ and $\operatorname{cge} A$ genes are designed in a way enabling for obtaining fusions with heterologous protein attached to the $\mathrm{C}$-terminus of the coat protein directly or via alpha-helical linker (-GGGEAAAKGGG-) [21]. Such set of vectors gives a flexibility in construction of strains producing recombinant spores. The efficiency of expression and surface display of heterologous protein depends on its nature. It is known, that in case of some protein fusions direct link between two partners may result in fusion instability or aggregation [22,23]. In case of spore surface display such situation would prevent coat protein-passenger protein fusion from incorporation into the spore coat structure. Linking of heterologous protein to the coat protein by a linker might help to solve these problems. A choice of type of fusion with spore coat protein gives an opportunity to optimize the display. 
Vectors for C-terminal fusions harbor a cot/cgeA gene cloned along with its original promoter and ribosome binding site (RBS). A cot/cgeA gene has no STOP codon but a multiple cloning site is located right at the end of the gene or just after the sequence coding for a peptide linker. It is important to clone a gene of interest along with its own STOP codon to ensure proper termination of translation.

Vectors for $\mathrm{N}$-terminal fusions have a multiple cloning site inserted in between START codon and the remaining part of a cot gene. In variants with linkers a linker coding sequence is inserted directly downstream of the multiple

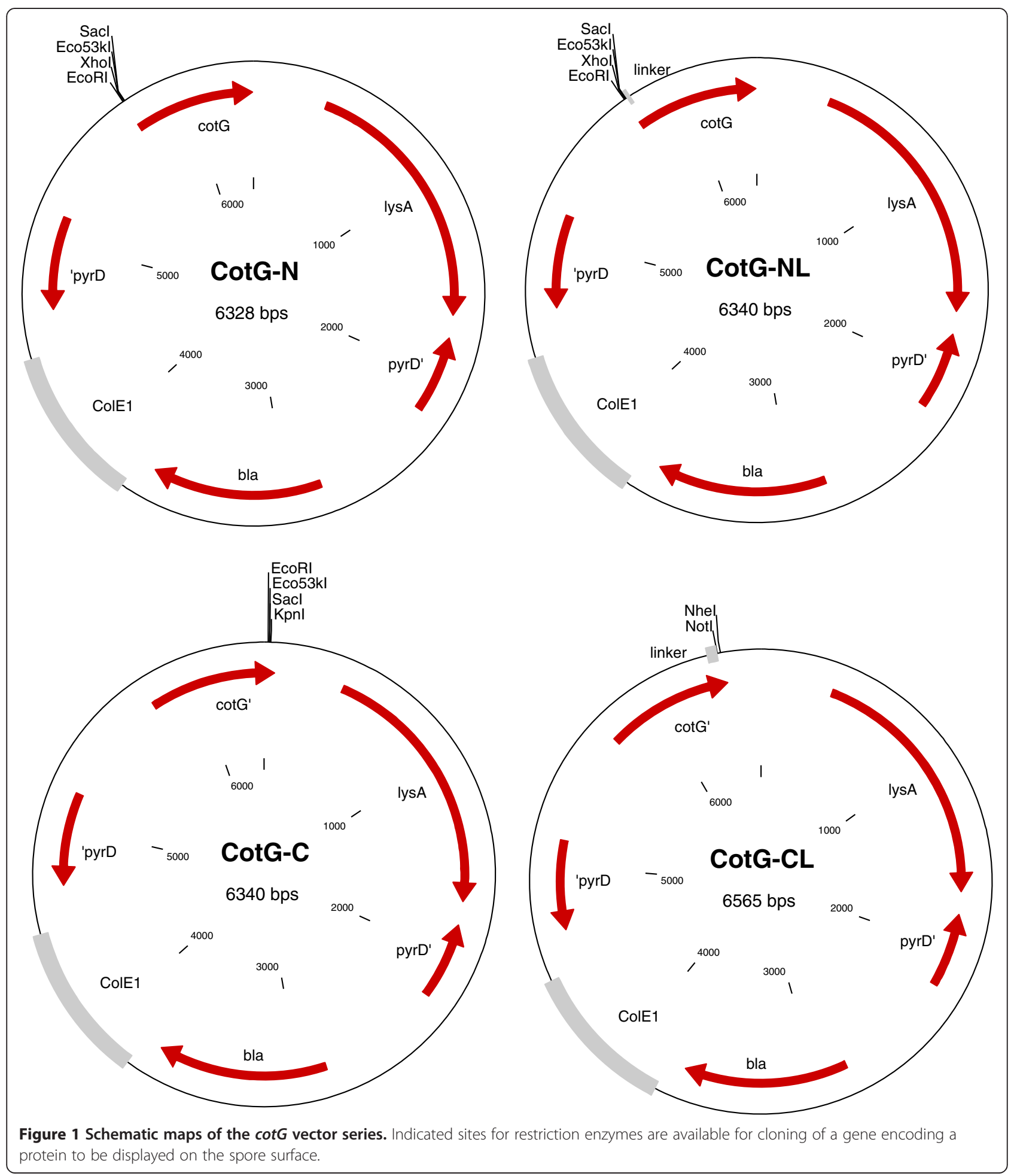


cloning site. In case of N-terminal fusion vectors it is important to verify, that a gene of interest is cloned in frame of the cot gene translation and it has no STOP codon.

Ectopic integration loci are selected as follows: pCotB, pCotZ and pCgeA vectors - amyE, pCotC vectors $l a c A$ and pCotG vectors - pyrD. All the loci are nonessential for growth of $B$. subtilis in normal conditions and are commonly used for introducing cloned genes or constructs into the chromosome of this bacterium. The use of different integration loci makes the system more flexible and enables designing a recombinant strains displaying on the spore surface three different fusions at the same time.

The following genes are used as selection markers in the vector system: $\mathrm{pCot} B$ - thr $C, \mathrm{pCot} C, \mathrm{pCotZ}, \mathrm{pCgeA}-$ $\operatorname{trp} C$ and pCotG - lys A. Recipient strains compatible with these vectors should be the auxotrophs for appropriate amino acids. The auxotrophy can be achieved by inactivation, deletion or complete knockout [24] of the gene used for selection. Selection of recombinant strains upon transformation can then be done using plates with minimal medium lacking threonine, tryptophan or lysine. As an example vectors of $\mathrm{pCotG}$ series are shown in Figures 1 and 2.

\section{Construction of $\mathrm{pCgeA}-\mathrm{CagA}$ vectors}

To test the system we have prepared two vectors for display of a fragment of Helicobacter pylori CagA protein (cytotoxic-associated gene A) in fusion with C-terminal end of CgeA protein. The heterologous part of the fusion encompassed 83 amino acids (residues 1146 to 1222) of CagA and was selected from the most immunogenic regions of this protein as designated by Antigen program (a part of EMBOSS package; http://emboss. sourceforge.net/). One vector enabled production of direct fusion of CgeA and CagA fragment, while in the other the heterologous part was connected via alphahelical linker. Obtained plasmid were named pAV05 (cgeA-cagA) and pAV03 (cgeA-linker-cagA) and used for transformation of Bacillus subtilis strain 168. Laboratory strain 168 is an auxotroph for tryptophan due to mutation in $\operatorname{trp} C$ gene. The presence of functional $\operatorname{trp} C$ gene (cloned from B. subtilis 3610) within the region, which is integrated into the $a m y E$ locus along with $\operatorname{cge} A-\operatorname{cag} A$ fusion upon successful recombination enabled us to select prototrophic recombinant strains (Figure 3).

Both strains and their isogenic parental strain 168 showed comparable sporulation and germination efficiencies and their spores were equally resistant to

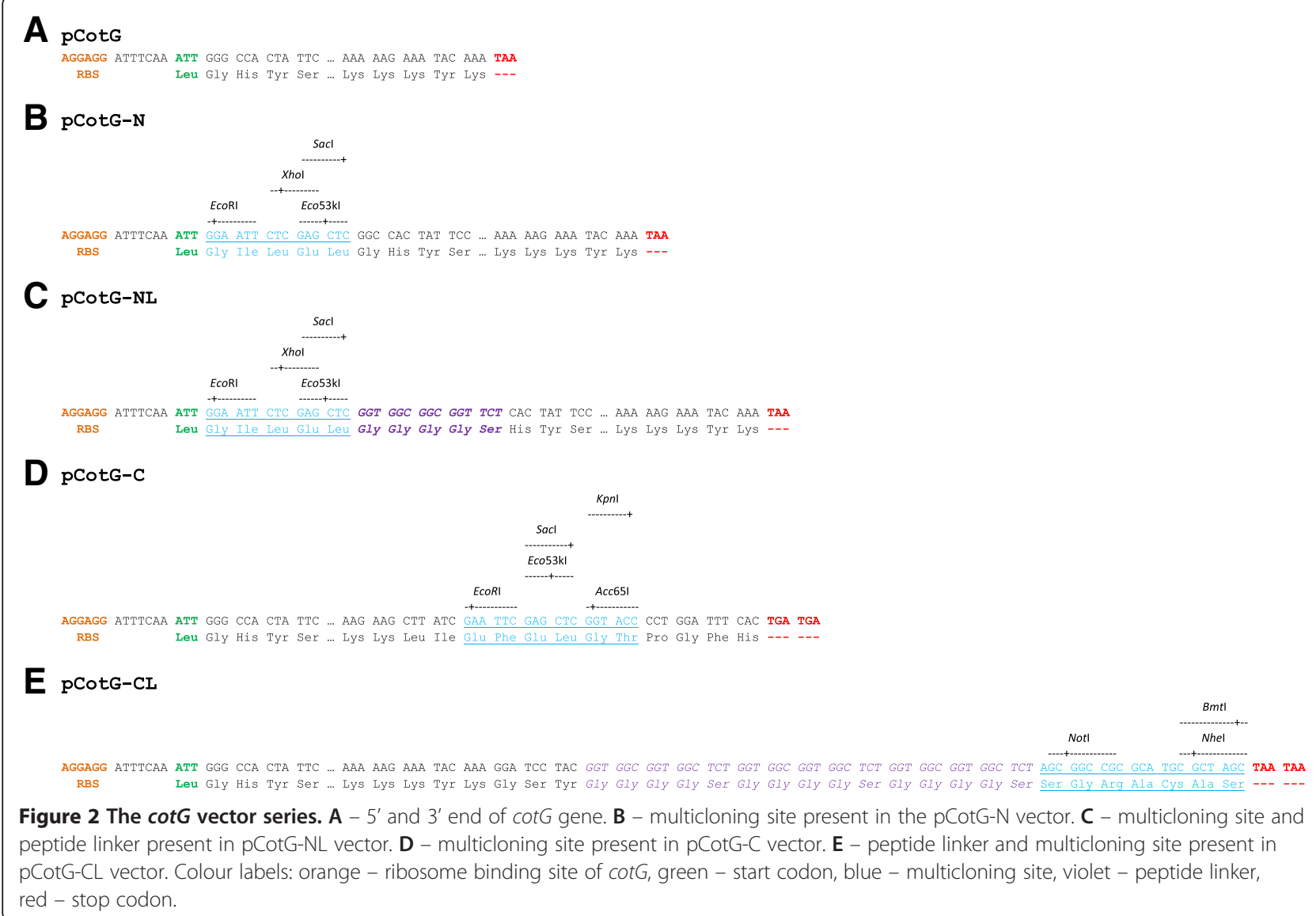




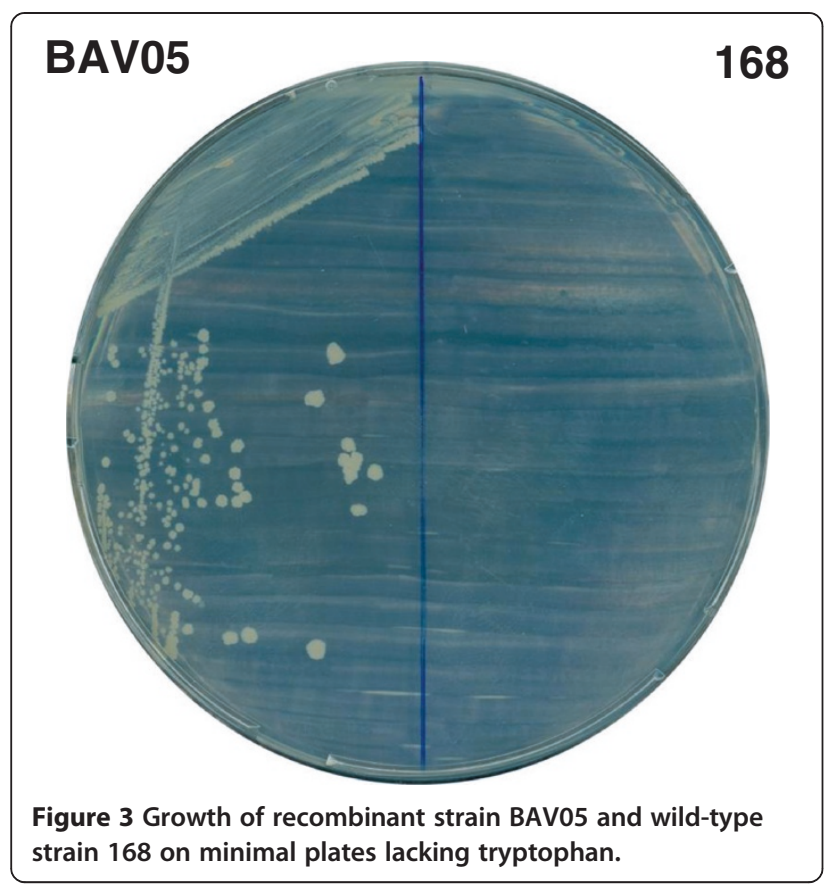

chloroform and lysozyme treatment (not shown). Therefore, limited to the spore properties that we have analyzed, the presence of CgeA-CagA and CgeA-linker-CagA fusions did not affect spore structure or functionality.

\section{Spore coat expression}

The localization of fusion proteins on the spore coat was tested by western blotting with anti-CgeA and antiCagA antibodies. The analysis of spore coat proteins purified from the wild type and recombinant strains BAV05 carrying fusion CgeA-CagA revealed the presence of an about 23-kDa band, which reacted with both
CgeA- and CagA-specific antibodies (Figure 4). In case of strain BAV07 (CgeA-linker-CagA) we observed an about 24-kDa band, which also reacted with both types of antibodies (Figure 4). Calculated molecular masses of fusion proteins are $22.8 \mathrm{kDa}$ for CgeA-CagA and $23.6 \mathrm{kDa}$ for fusion with linker and correspond well with the results obtained in the western blotting. CgeAspecific antibodies produced an about 14-kDa band corresponding to native $\mathrm{CgeA}$ protein, as well as several bands of higher molecular masses, which most probably represent multimers of CgeA protein since they cannot be visualised in hybridizations with spore coat proteins isolated from the strain BAV08 with inactivation of $c g e A$ gene (Figure 4A, lane 2).

\section{Surface display}

The surface localization of CgeA-CagA (BAV05) and CgeA-GGGEAAAKGGG-CagA (BAV07) fusion proteins was analyzed by immunofluorescence microscopy of dormant spores of wild type and recombinant strains using anti-CgeA and anti-CagA primary antibodies followed by anti-mouse IgG-Cy3 (Jackson ImmunoResearch Laboratories, Inc). We observed a fluorescent signal around purified dormant spores of both BAV05 and BAV07 strains (Figure 5). These results indicate that both fusion proteins are present on the spore coat surface and are available for antibody binding. It is worth notifying, that fluorescent signal observed in case of BAV07 spores is stronger than in case of BAV05, what clearly suggest, that anchoring of CagA to CgeA protein via helical linker increases the efficiency of surface display of heterologous protein.

\section{Conclusions}

Presented set of vectors is a versatile system for spore surface display of heterologous proteins. Since the
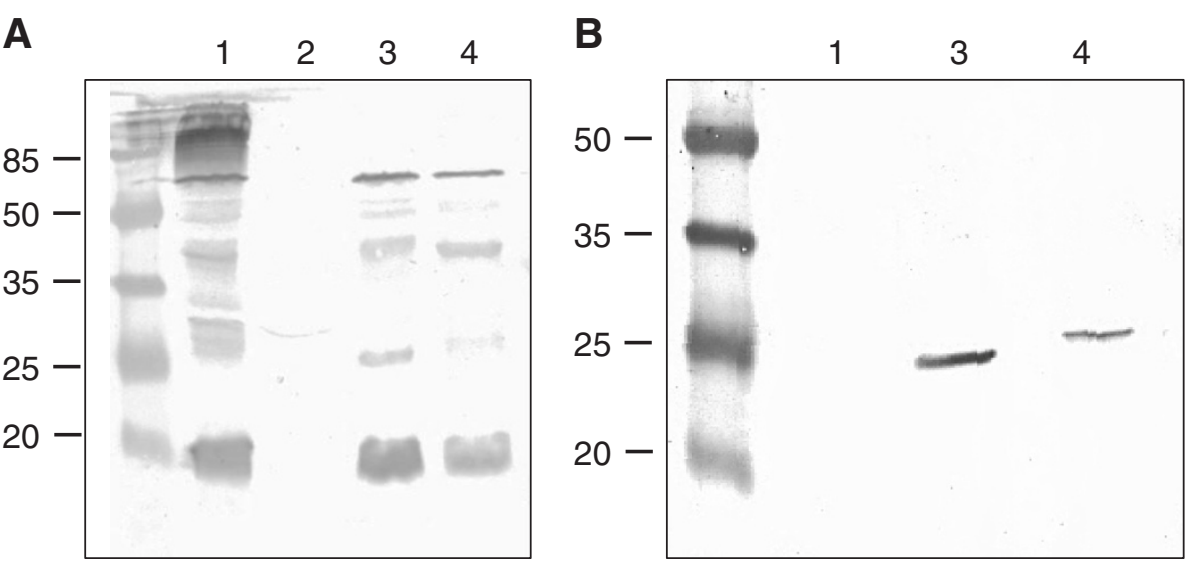

Figure 4 Western blotting analysis of expression of the cgeA-cagA fusion gene. Spore coat proteins were extracted and analysed by western blotting with anti-CgeA (panel A) or anti-CagA (panel B) antibodies. Spore coat proteins from spores of the 168 (lane 1), the BAV08 (inactivation of cgeA) (lane 2), the BAV05 (fusion CgeA-CagA) (lane 3) and the BAV07 (fusion CgeA-linker-CagA) (lane 4) strains. Each lane of panel $\mathbf{A}$ and $\mathbf{B}$ was loaded with $20 \mu \mathrm{g}$ of total proteins. 


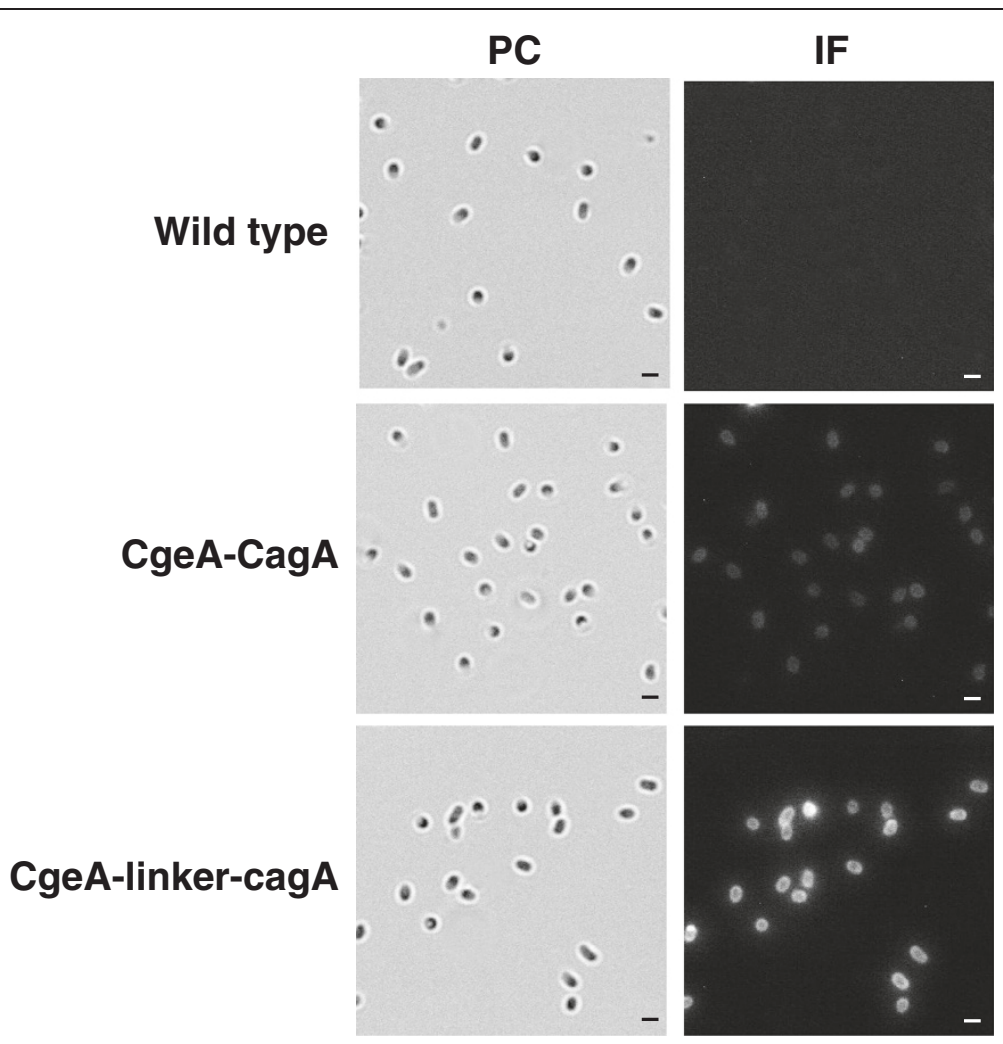

Figure 5 Localisation of fusion proteins as assessed by immunofluorescence microscopy. Purified, free spores of wild type strain 168, BAV05 (CgeA-CagA), BAV07 (CgeA-linker-CagA) were visualised by phase contrast (PC) and immunofluorescence (IF) microscopy. The spores were incubated with mouse anti-CagA, followed by anti-mouse lgG-Cy3 conjugates. The same exposure time was used for all IF images. Black and white scale bars $-1 \mu \mathrm{m}$.

successful presentation of proteins on the spore surface depends on its nature, as well as, the properties of obtained fusions it may be necessary to design a panel of plasmids with different spore coat proteins as anchors including or not a peptide linker to enhance the display. A variety vectors included in the presented system facilitates such optimization. It is also important to point out, that all Cot coat proteins used in the system has already successfully been utilized in such applications. Additionally, another coat protein, CgeA, turned out to be useful for presentation of heterologous proteins.

\section{Methods}

\section{Bacterial strains and transformation}

Plasmid amplifications for nucleotide sequencing and subcloning experiments were performed with Escherichia coli strains DH5 $\alpha$ [25] or BL21 (New England Biolabs, USA). Bacterial strains were transformed by previously described procedures: $\mathrm{CaCl}_{2}$-mediated transformation of $E$. coli competent cells [26] and transformation of B. subtilis [27]. Bacillus subtilis 168 was used for construction of recombinant strains.

\section{Construction of gene fusions}

DNA coding for coat proteins was PCR amplified using the $B$. subtilis 168 chromosome as a template and oligonucleotides listed in Additional file 1: Table S1 as primers. Amplification products were cloned into the vectors listed in the Additional file 1: Table S1. In case of vectors for $\mathrm{N}$ terminal fusions promoter regions of corresponding coat protein genes were separately PCR amplified using oligonucleotides listed in Additional file 1: Table S1 as primers and cloned into appropriate vectors. The DNA coding for lys $A$ and $t h r C$ trophic genes were PCR amplified using appropriate oligonucleotides as primers (Additional file 1: Table S1) and chromosomal DNA of B. subtilis strain 168. The $\operatorname{trp} C$ gene was amplified with using chromosomal DNA of B. subtilis 3610 strain with addition of the $p_{r r n O}$ promoter sequence included in the primers. Obtained PCR fragments harboring a trophic gene along with the promoter were cloned into the proper plasmids (Additional file 1: Table S1). Where necessary the MCS was introduced by cloning a DNA fragment obtained upon annealing of appropriate oligonucleotides (Additional file 1: Table S1). The $\mathrm{pCot} B$ vector set was constructed using synthetic gene 
as described in the additional file. The complete list of final vectors is presented in Table 1.

For construction of $H$. pylori CagA-presenting spores following plasmid was prepared. A 227 bp DNA fragment encoding part of CagA was PCR amplified using Helicobacter pylori NCTC 11637 chromosome as a template and oligonucleotides cagA-F and cagA-R (Table 2) as primers. The PCR product was sequentially digested with BamHI and KpnI and cloned in frame to the 3' end of the cgeA gene carried by plasmid pCgeA-C or pCgeA$\mathrm{CL}$ yielding plasmids pAV05 and pAV03.

\section{Chromosomal integration}

Appropriate plasmids were linearized by digestion with a single cutting restriction enzyme. Linearized DNA was used to transform competent cells of the B. subtilis strain 168. The bacteria were plated on solidified Belitzky minimal medium without tryptophan [28]. Prototrophic clones were the result of a double-crossover recombination event, resulting in the interruption of the non-essential $a m y E$ gene on the B. subtilis chromosome. Several prototrophic clones were tested by PCR using chromosomal DNA as a template and oligonucleotides AmyS and AmyA [29] to prime the reaction. Selected clones were called BAV05 (CgeA-CagA) and BAV07 (CgeA-linker-CagA) and stored for further research.

\section{Construction of the strain with inactivation of the cgeA gene}

A 316 bp fragment of the cgeA gene was PCR amplified using chromosomal DNA of B. subtilis strain 168 as a template and oligonucleotides $\mathrm{i}-\operatorname{cgeA}-\mathrm{F}$ and $\mathrm{i}-\operatorname{cgeA}-\mathrm{R}$
(Table 2) as primes. The obtained PCR product was digested with enzymes HindIII and BamHI and cloned into the pMUTIN4 vector [30]. The resulting plasmid, pAGW6, was verified by restriction analysis and used for transformation of B. subtilis strain 168. Obtained erythromycinresistant colonies were the result of single crossing-over recombination event leading to the insertion of the plasmid into the chromosome of recipient strain. Selected colonies were PCR-verified for the correctness of the cgeA gene inactivation. The resulting strain was called BAV08 and stored for further research.

\section{Preparation of spores}

Sporulation was induced by the exhaustion method in Difco sporulation medium (DSM) as described elsewhere [31]. Sporulating cultures were harvested $24 \mathrm{~h}$ after the initiation of sporulation and purified using a lysozyme treatment to break up any residual sporangial cells, followed by washing steps in $1 \mathrm{M} \mathrm{NaCl}, 1 \mathrm{M} \mathrm{KCl}$ and water (twice each), as described by Nicholson \& Setlow [31]. PMSF (0.05 M) was included to inhibit proteolysis. After the final suspension in water, spores were treated at $65^{\circ} \mathrm{C}$ for $1 \mathrm{~h}$ to kill any residual cells. The spore suspension was titrated immediately for determination of c.f.u./ml before freezing at $-22^{\circ} \mathrm{C}$. Using this method, we could reliably produce $6 \times 10^{10}$ spores in 1 liter of DSM culture.

\section{Extraction of spore coat proteins}

Spore coat proteins were extracted from $50 \mu$ of a suspensions of spores at high density $\left(1 \times 10^{10}\right.$ spores per $\left.\mathrm{ml}\right)$ using a decoating extraction buffer as described elsewhere

\section{Table 1 List of vectors in the system}

\begin{tabular}{|c|c|c|c|}
\hline Name & Coat gene and type of fusion & Integration site and trophic gene & Accession number \\
\hline $\mathrm{pCotB-N}$ & $\cot B \mathrm{~N}$-terminal & amyE thrC & [GenBank:KF933395] \\
\hline pCotB-NL & $\cot B \mathrm{~N}$-terminal + linker & & [GenBank:KF933396] \\
\hline pCotB-C & $\cot B$ C-terminal & & [GenBank:KF933397] \\
\hline $\mathrm{pCotB}-\mathrm{CL}$ & $\operatorname{cotB} C$-terminal + linker & & [GenBank:KF933398] \\
\hline pCotC-N & $\cot C \mathrm{~N}$-terminal & lacA trpC & [GenBank:KF933399] \\
\hline pCotC-NL & $\operatorname{cotC} \mathrm{N}$-terminal + linker & & [GenBank:KF933400] \\
\hline $\mathrm{pCot} C-\mathrm{C}$ & cotC C-terminal & & [GenBank:KF933401] \\
\hline $\mathrm{pCotC}-\mathrm{CL}$ & cotC C-terminal + linker & & [GenBank:KF933402] \\
\hline pCotG-N & $\operatorname{cotG} \mathrm{N}$-terminal & pyrD lys A & [GenBank:KF933403] \\
\hline pCotG-NL & $\operatorname{cotG} \mathrm{N}$-terminal + linker & & [GenBank:KF933404] \\
\hline pCotG-C & $\operatorname{cotG}$ C-terminal & & [GenBank:KF933405] \\
\hline $\mathrm{pCotG}-\mathrm{CL}$ & $\operatorname{cotG}$ C-terminal + linker & & [GenBank:KF933406] \\
\hline pCotZ-C & $\operatorname{cotZ}$ C-terminal & amyE trpC & [GenBank:KF933407] \\
\hline pCotZ-CL & cotZ C-terminal + linker & & [GenBank:KF933408] \\
\hline pCgeA-C & cgeA C-terminal & amyE trpC & [GenBank:KF933393] \\
\hline $\mathrm{pCgeA}-\mathrm{CL}$ & cgeA C-terminal + linker & & [GenBank:KF933394] \\
\hline
\end{tabular}


Table 2 Oligonucleotides list

\begin{tabular}{|c|c|c|}
\hline Name & Sequence $\left(5^{\prime}-3^{\prime}\right)$ & Restriction site \\
\hline pRSETAcgeA-F & GTGTGGATCCAGCTCTGAAAATGC & BamHI \\
\hline pRSETAcgeA-R & CGGGAATTCTGAAAAGAACGTAACG & EcoRl \\
\hline pLATE52cagA-F & GGTTGGGAATTGCAAGGTATGCTAACGCAAAAAAACCCTG & None \\
\hline pLATE52cagA-R & GGAGATGGGAAGTCATTATCCTGTAGAAAATGCATTGGC & None \\
\hline i-cgeA-F & CCCAAGCTTACAGAAGGAGGAGAAAATATG & HindllI \\
\hline$i-c g e A-R$ & CGCGGATCCITTCTACTTTGTCTACATC & $\mathrm{BamHI}$ \\
\hline $\operatorname{cag} A-F$ & CGCGGATCCGGTATGCTAACGCAAAAAAAC & $\mathrm{BamHI}$ \\
\hline cagA-R & CGGGGTACCTTATCCTGTAGAAAATGCATTGGC & Kpnl \\
\hline
\end{tabular}

In bold are the recognition sites for the restriction enzymes indicated in the table. Oligonucleotides used for construction of vectors of the system are listed in Additional file 1: Table S1.

[32]. Extracted proteins were assessed for integrity by SDS-polyacrylamide gel electrophoresis (PAGE) and for concentration by two independent methods: the Pierce BCA Protein Assay (Pierce, USA) and the BioRad DC Protein Assay kit (Bio-Rad, USA).

\section{Western blotting analyses}

Extracted proteins were separated in 12\% denaturing polyacrylamide gels, electrotransferred onto a nitrocellulose filter (Roti-NC; ROTH) and used for Western blotting by standard procedures. Western blot filters were visualized by developing with $\mathrm{BCIP} / \mathrm{NBT}$ according to the manufacturer's instructions (Thermo Scientific).

\section{Immunofluorescence microscopy}

Samples were fixed directly in the medium as described by Harry et al. [33], with the following modifications: spores were suspended in TE buffer $[20 \mathrm{mM}$ Tris $/ \mathrm{HCl}$ (pH 7.5), $10 \mathrm{mM}$ EDTA] containing $2 \mathrm{mg}$ lysozyme ml. After 3 min of incubation, three washes in PBS ( $\mathrm{pH} 7.4$ ) were performed before blocking with $3 \%$ skimmed milk in PBS for $30 \mathrm{~min}$ at room temperature and washing another three times in PBS. Samples were incubated overnight at $4^{\circ} \mathrm{C}$ with mouse anti-CagA antibody, washed three times and then incubated with anti-mouse Cy3conjugated IgG (Jackson ImmunoResearch Laboratories) overnight at $4^{\circ} \mathrm{C}$. After three washes with PBS, samples were loaded on microscope slides previously coated with poly-L-lysine (Sigma). The coverslips were mounted on a microscope slide and viewed using a Zeiss Axioplan fluorescence microscope with the same exposure time for all samples. Images were captured using a camera connected to the microscope, processed with Corel Photo-Paint software and saved in TIFF format.

\section{Purification of $\mathrm{CgeA}$ and CagA and antibody production} The cgeA gene of $B$. subtilis was PCR amplified using chromosomal DNA as a template and oligonucleotides pRSETAcgeA-F and pRSETAcgeA-R (Table 2) as primes. The obtained PCR product of 415 bp was digested with enzymes EcoRI and BamHI and cloned into the commercial vector pRSETA (Invitrogene). The resulting plasmid, pAN17, was verified by restriction analysis and nucleotide sequencing. The protein was purified and used for antibody production following method described previously [21].

The fragment of cagA gene of $H$. pylori was PCR amplified using chromosomal DNA as a template and oligonucleotides pLATE52cagA-F and pLATE52cagA-R (Table 2) as primes. The obtained PCR product of $261 \mathrm{bp}$ was cloned into the commercial vector pLATE 52 (Thermo Scientific, Lithuania) using aLICator Ligation Independent Cloning and Expression System (Thermo Scientific). The resulting plasmid, pKH143, was verified by restriction analysis and nucleotide sequencing. The protein was purified and used for antibody production following method described previously [21].

\section{Ethics statement}

This study was carried out in strict accordance with the recommendations in the institutional and national guidelines for animal care and use. The protocol was approved by the Committee on the Ethics of Animal Experiments of the Medical University of Gdańsk (Permit Number: 4/2010). All surgery was performed under isoflurane anesthesia, and all efforts were made to minimize suffering.

\section{Additional file}

Additional file 1: Table S1. Construction of the vectors set.

\section{Competing interests}

AG, TŁ, MO and $\mathrm{KH}$ are authors of Polish patent application no P.403468 filled on 08/04/2013. MS, IP, KH, Al and MO are authors of Polish patent application no P.406271 filled on 26/11/2013, both entitled "Integration vectors, host cell transformed with integration vectors and application of integration vectors and host cell for presentation of fusion proteins on the surface of Bacillus subtilis spores". Patent applications do not alter the authors' adherence to all the Microbial Cell Factories polices on sharing data and materials. 


\section{Authors' contributions}

$\mathrm{Al}$ - participated in study design, constructed $\mathrm{PCotG}$ vectors set and wrote the manuscript, IP - constructed pCotB vectors set, MS - constructed pCotC vectors set, $\mathrm{AG}$ - constructed $\mathrm{pCotZ}$ and $\mathrm{pCgeA}$ vectors sets and prepared pCgeA-CagA plasmid, TŁ - constructed pTL01 vector, MO - conceived the study, participated in its design and coordination and helped to draft the manuscript, $\mathrm{KH}$ - participated in study design and performed CagA spore surface analysis. All authors read and approved the final manuscript.

\section{Acknowledgements}

The research was supported by the Polish National Center for Research and Development grant no R12 014310 and by the Foundation for Polish Science grant HOMING PLUS/2010-2/3. Publication costs were covered by the EU FP7 project MOBI4Health, GA. 316094.

Received: 17 January 2014 Accepted: 18 February 2014

Published: 24 February 2014

\section{References}

1. Daunert S, Barrett G, Feliciano JS, Shetty RS, Shrestha S, Smith-Spencer W: Genetically engineered whole-cell sensing systems: coupling biological recognition with reporter genes. Chem Rev 2000, 100:2705-2738.

2. Georgiou G, Stathopoulos C, Daugherty PS, Nayak AR, Iverson BL: Curtiss 3rd R: display of heterologous proteins on the surface of microorganisms: from the screening of combinatorial libraries to live recombinant vaccines. Nat Biotechnol 1997, 15:29-34.

3. Liu X, Germaine KJ, Ryan D, Dowling DN: Whole-cell fluorescent biosensors for bioavailability and biodegradation of polychlorinated biphenyls. Sensors (Basel) 2010, 10:1377-1398.

4. Wu CH, Mulchandani A, Chen W: Versatile microbial surface-display for environmental remediation and biofuels production. Trends Microbiol 2008, 16:181-188.

5. Popham DL: Specialized peptidoglycan of the bacterial endospore: the inner wall of the lockbox. Cell Mol Life Sci 2002, 59:426-433.

6. Henriques AO, Moran CP Jr: Structure, assembly, and function of the spore surface layers. Annu Rev Microbiol 2007, 61:555-588.

7. Driks A: The bacillus anthracis spore. Mol Aspects Med 2009, 30:368-373.

8. McKenney PT, Eichenberger P: Dynamics of spore coat morphogenesis in Bacillus subtilis. Mol Microbiol 2012, 83:245-260.

9. Warth AD, Ohye DF, Murrell WG: The composition and structure of bacterial spores. J Cell Biol 1963, 16:579-592.

10. Mckenney PT, Driks A, Eskandarian HA, Grabowski P, Guberman J, Wang KH, Gitai Z, Eichenberger P: A distance-weighted interaction map reveals a previously uncharacterized layer of the Bacillus subtilis spore coat. Curr Biol 2010, 20:934-938.

11. McKenney PT, Driks A, Eichenberger P: The Bacillus subtilis endospore: assembly and functions of the multilayered coat. Nat Rev Microbiol 2013, 11:33-44.

12. Imamura $\mathrm{D}$, Kuwana $\mathrm{R}$, Takamatsu $\mathrm{H}$, Watabe $\mathrm{K}$ : Proteins involved in formation of the outermost layer of Bacillus subtilis spores. J Bacteriol 2011, 193:4075-4080.

13. Isticato R, Cangiano G, Tran HT, Ciabattini A, Medaglini D, Oggioni MR, De Felice M, Pozzi G, Ricca E: Surface display of recombinant proteins on Bacillus subtilis spores. J Bacteriol 2001, 183:6294-6301.

14. Duc LH, Hong HA, Atkins HS, Flick-Smith HC, Durrani Z, Rijpkema S, Titball RW, Cutting SM: Immunization against anthrax using Bacillus subtilis spores expressing the anthrax protective antigen. Vaccine 2007, 25:346-355.

15. Hinc K, Isticato R, Dembek M, Karczewska J, Iwanicki A, PeszyL ska-Sularz G, De Felice M, Obuchowski M, Ricca E: Expression and display of UreA of helicobacter acinonychis on the surface of bacillus subtilis spores. Microb Cell Fact 2010, 9:2.

16. Mao L, Jiang S, Li G, He Y, Chen L, Yao Q, Chen K: Surface display of human serum albumin on Bacillus subtilis spores for oral administration. Curr Microbiol 2012, 64:545-551.

17. Kim J-H, Roh C, Lee C-W, Kyung D, Choi S-K, Jung H-C, Pan J-G, Kim B-G: Bacterial surface display of GFP (uv) on Bacillus subtilis spores. J Microbiol Biotechnol 2007, 17:677-680.

18. Kim J-H, Lee C-S, Kim B-G: Spore-displayed streptavidin: a live diagnostic tool in biotechnology. Biochem Biophys Res Commun 2005, 331:210-214.
19. Kwon SJ, Jung H-C, Pan J-G: Transgalactosylation in a water-solvent biphasic reaction system with beta-galactosidase displayed on the surfaces of Bacillus subtilis spores. Appl Environ Microbiol 2007, 73:2251-2256

20. Hinc K, Iwanicki A, Obuchowski M: New stable anchor protein and peptide linker suitable for successful spore surface display in B. subtilis. Microb Cell Fact 2013, 12:22.

21. Negri A, Potocki W, Iwanicki A, Obuchowski M, Hinc K: Expression and display of Clostridium difficile protein FliD on the surface of Bacillus subtilis spores. J Med Microbiol 2013, 62:1379-1385.

22. Prescott M, Nowakowski S, Nagley P, Devenish RJ: The length of polypeptide linker affects the stability of green fluorescent protein fusion partners. Anal Biochem 1999, 273:305-307.

23. Chang H-C, Kaiser CM, Hartl U, Barral JM: De novo folding of GFP fusion proteins: high efficiency in eukaryotes but not in bacteria. J Mol Biol 2005, 353:397-409.

24. Bloor AE, Cranenburgh RM: An efficient method of selectable marker gene excision by Xer recombination for gene replacement in bacterial chromosomes. Appl Environ Microbiol 2006, 72:2520-2525.

25. Woodcock DM, Crowther PJ, Doherty J, Jefferson S, DeCruz E, NoyerWeidner M, Smith SS, Michael MZ, Graham MW: Quantitative evaluation of Escherichia coli host strains for tolerance to cytosine methylation in plasmid and phage recombinants. Nucleic Acids Res 1989, 17:3469-3478.

26. Green MR, Sambrook J: Molecular cloning. A laboratory manual. Cold Spring Harbor Laboratory Press: Cold Spring Harbor; 2012.

27. Julkowska D, Obuchowski M, Holland IB, Séror SJ: Comparative analysis of the development of swarming communities of Bacillus subtilis 168 and a natural wild type: critical effects of surfactin and the composition of the medium. J Bacteriol 2005, 187:65-76.

28. Stülke J, Hanschke R, Hecker M: Temporal activation of beta-glucanase synthesis in Bacillus subtilis is mediated by the GTP pool. I Gen Microbiol 1993, 139:2041-2045.

29. Isticato R, Esposito G, Zilhao R, Nolasco S, Cangiano G, De Felice M, Henriques AO, Ricca E: Assembly of multiple CotC forms into the Bacillus subtilis spore coat. J Bacteriol 2004, 186:1129-1135.

30. Vagner V, Dervyn E, Ehrlich SD: A vector for systematic gene inactivation in Bacillus subtilis. Microbiology 1998, 144:3097-3104.

31. Nicholson WL, Setlow P: Dramatic increase in negative superhelicity of plasmid DNA in the forespore compartment of sporulating cells of Bacillus subtilis. J Bacteriol 1990, 172:7-14.

32. Monroe A, Setlow P: Localization of the transglutaminase cross-linking sites in the Bacillus subtilis spore coat protein GerQ. J Bacteriol 2006, 188:7609-7616.

33. Harry EJ, Pogliano K, Losick R: Use of immunofluorescence to visualize cell-specific gene expression during sporulation in Bacillus subtilis. J Bacteriol 1995, 177:3386-3393.

doi:10.1186/1475-2859-13-30

Cite this article as: Iwanicki et al:: A system of vectors for Bacillus subtilis spore surface display. Microbial Cell Factories 2014 13:30.

\section{Submit your next manuscript to BioMed Central and take full advantage of:}

- Convenient online submission

- Thorough peer review

- No space constraints or color figure charges

- Immediate publication on acceptance

- Inclusion in PubMed, CAS, Scopus and Google Scholar

- Research which is freely available for redistribution 